\title{
O FESTIVAL DO RISO NAS METAMORFOSES DE APULEIO: UM ARQUÉTIPO DE FESTIVAL GRECO-ROMANO? APLICAÇÃO DE UMA ABORDAGEM POLITÉTICA
}

BRAULIO COSTA PEREIRA ${ }^{1}$

Resumo: No presente trabalho, apresenta-se uma análise do episódio do Festival do Riso nas Metamorfoses de Apuleio (II, 31 - III, 18) à luz da abordagem politética demonstrada por Jon W. Iddeng para a definição e classificação dos festivais greco-romanos. Pretende-se demonstrar como Apuleio, ao descrever um festival que se acredita completamente fictício, utilizou-se de seus conhecimentos e experiências pessoais do que seria um festival para a construção do episódio, criando assim um modelo arquetípico de festival grecoromano. O Festival do Riso apresentaria, portanto, características centrais dos festivais greco-romanos como são definidos por Iddeng (2012).

Palavras-chave: Apuleio, Metamorfoses, Festival do Riso, festival greco-romano

\footnotetext{
${ }^{1}$ Doutorando e Mestre do Programa de Pós-Graduação em Letras Clássicas da Universidade Federal do Rio de Janeiro, orientado pelo Prof. Dr. Anderson de Araújo Martins Esteves e-mail: brauliocostapereira@yahoo.com.br
}

\section{INTRODUÇÃO}

No final do segundo e início do terceiro livro das Metamorfoses de Apuleio encontra-se uma curiosa narrativa: o personagem principal, Lúcio, é convidado durante um banquete a participar de um festival religioso a ser realizado no dia seguinte na cidade de Hípata, onde ele se encontrava hospedado. Lúcio aceita a oferta sem maiores questionamentos e, já bêbado, volta acompanhado de um escravo à casa de seu anfitrião, Milão. Na entrada da casa, Lúcio se depara com três homens fortes que parecem estar forçando a porta e, supondo que eram ladrões, inicia um combate. Tendo conseguido matar os três estranhos, ele entra na casa e é recebido por sua amante Fótis, que também é uma criada de Milão. Lúcio, exausto, adormece (Met II, 31-32).

No dia seguinte, magistrados vão até a casa de Milão e levam Lúcio para ser julgado pela morte de três cidadãos (Met III, 1). Primeiramente, ele é levado até o tribunal, no Fórum de Hípata, mas o clamor das pessoas que queriam acompanhar o julgamento e consideravam o espaço muito pequeno para seu número faz com que os magistrados o 
levem ao teatro da cidade. Ao longo do caminho, Lúcio se sente como uma vítima sacrificial e repara que toda a cidade o acompanha com curiosidade e, o que é mais estranho, aparentemente gargalhando (Met III, 2).

Chegando ao teatro, depois que todos se acomodam, Lúcio é formalmente acusado por um dos magistrados, e em seguida profere um discurso em sua própria defesa, admitindo ter cometido o crime, mas argumentando que o fizera para defender a casa de seu anfitrião (Met III, 3-6). Os magistrados não são convencidos, e, supondo impossível que apenas um homem tivesse dado cabo de três jovens fortes, determinam que Lúcio seja submetido a tortura para revelar a identidade de seus cúmplices (o escravo que o acompanhara havia desaparecido). 0 desespero de Lúcio chega ao seu auge quando duas mulheres, dizendo serem parentes dos homens mortos, trazem consigo os corpos dos falecidos, cobertos por uma mortalha. Os magistrados exigem que Lúcio retire a mortalha para que todos vejam a gravidade do crime e, inspirados pela revolta, possam proceder à tortura com renovada tenacidade. Quando Lúcio retira a mortalha, descobre, para sua surpresa, que em lugar de corpos verdadeiros havia ali três grandes odres de vinho vazios e perfurados nos mesmos lugares em que Lúcio julgava ter enterrado a espada nos corpos dos três bandidos (Met III, 7-9).

Nesse momento todos os que até então seguravam o riso começam a gargalhar abertamente (Met III, 10). Consternado, Lúcio é levado de volta para casa por Milão, que explica que a situação toda fora uma brincadeira, uma encenação que fazia parte do Festival do Riso. Os cidadãos de Hípata estão muito satisfeitos com a participação de Lúcio em sua celebração e chegam a dizer que farão uma estátua em sua homenagem - préstimo que Lúcio prontamente recusa (Met III, 11). Mais tarde, Fótis esclarece os detalhes do ocorrido, explicando que sua patroa Pânfila - uma feiticeira, e esposa de Milão - havia enfeitiçado por engano os odres de vinho, conferindo-lhes vida. A intenção original de Pânfila era seduzir com magia um jovem rapaz, e para isso ela pedira a Fótis que Ihe trouxesse fios de seu cabelo. Falhando nessa tarefa, Fótis trouxe pelos retirados dos odres para não voltar para casa de mãos vazias. O feitiço que atrairia o jovem acabou "atraindo" os odres, e por isso eles tentavam entrar na casa de Milão (Met III, 13-18).

O Festival do Riso é um episódio intrigante nas Metamorfoses de Apuleio. A natureza peculiar da narrativa, que trata de um evento, em princípio, muito diferente de qualquer festival de que se tenha notícia na Antiguidade, levou os estudiosos a interpretar essa passagem a partir de diferentes pontos de vista. Tradicionalmente, são feitos diversos paralelos entre este episódio e outras passagens das Metamorfoses: somos tentados a comparar o Festival do Riso e o Festival de Ísis (Met. XI), assim como o julgamento de Lúcio parece ser revisitado nos livros dedicados a Cupido e Psiquê (Met. IV-VI), nos quais a protagonista, também marcada pela curiosidade que Ihe causaria a ruína, é submetida a um julgamento perante os deuses igualmente realizado num teatro. Há também interpretações que escapam ao texto das Metamorfoses e enxergam na passagem uma referência à vida do próprio Apuleio, que também teve de se defender publicamente de acusações feitas a ele. P.G. Walsh considera o episódio uma paródia do procedimento e dos discursos legais típicos (WALSH, 1970, p. 58).

Algumas narrativas presentes nas Metamorfoses têm valor como descrições de eventos religiosos da Antiguidade. No entanto, o Festival do Riso não costuma ser analisado por essa chave de interpretação, talvez pelo fato de os estudiosos entenderem a passagem como completamente fictícia: não há registro de nenhum festival dedicado ao deus Riso na Tessália, e a própria existência de uma divindade como essa na religião grega é questionável. Embora haja referências a personificações do Riso como divindade em alguns textos clássicos², é pouco provável que o Risus descrito por Apuleio tenha sido verdadeiramente cultuado. Mesmo assim, existe um interesse na peculiaridade do Festival e nas descrições feitas por Apuleio ao longo da narrativa -

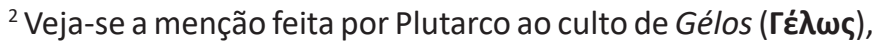
o Riso, em Esparta, na vida de Licurgo (Lyc. 25.2) 
como a comparação de Lúcio a uma vítima levada para o sacrifício - que parecem remeter a uma atmosfera de religiosidade quando submetidas a um olhar detido.

Um dos mais antigos trabalhos a abordar o Festival do Riso com a intenção de tratar da religiosidade do evento é o artigo de 1919 de D. S. Robertson, A Greek Carnival, que apresenta o Festival do Riso como um evento possivelmente baseado nas Hilaria, festival dedicado a Átis e Cibele. O autor reconhece a série de elementos presentes no episódio que caracterizariam um festival de ares carnavalescos ocorrido na primavera, ainda que não seja possível determinar com exatidão que a inspiração principal do Festival do Riso tenha sido as Hilaria. Ele também considera Lúcio um pharmakós, um bode expiatório que, apesar de estrangeiro, era próximo o bastante da comunidade para carregar seus pecados.

Parece correto, no entanto, concluir que a história é baseada num verdadeiro festival de primavera, que Apuleio (ou seu modelo grego) podem ter eles próprios testemunhado, e que esse festival incluía (1) a condução de um Pharmakos ao redor da cidade; (2) uma falsa luta, na qual um adversário foi morto; (3) uma lamentação; (4) a revelação de que a vítima não estava morta e (5) a oferta pública de honras ao vencedor ou à vítima revivida. ${ }^{3}$

Essas noções são retomadas por Thomas Habinek, que enxerga o Festival do Riso como parte de um rito de passagem que se estende por diversos festivais ao longo da narrativa (HABINEK, 1990, p. 53-55). Mais recentemente, Stavros Frangoulidis demonstrou a possibilidade de encarar o Festival do Riso como um ritual de integração à comunidade, indo de encontro à noção de que Lúcio seria um pharmakós:

\footnotetext{
3 "It seems fair, however, to conclude that the whole story is based on a real spring festival, which Apuleius (or his Greek model) may themselves have witnessed: and that this festival included (1) the leading of a Pharmakos round the town; (2) a sham-fight in which one adversary was killed; (3) a lamentation; (4) the revelation that the victim was not dead, and (5) the public bestowal of honours on the victor or on the revived victim" (ROBERTSON, 1919, p. 115).
}

Meu objetivo no que se segue é confrontar a visão prevalente do Festival do Riso como um ritual de expiação e argumentar em vez disso que a narrativa de Met. 3.1 - 12 representa um tipo de ritual de integração encenado no teatro. Nesse espaço público, Lúcio e todos os outros participantes atuam na performance de papéis rituais, cujo resultado leva não à sua expulsão da comunidade de Hípata, mas antes a uma proposta de integração a ela. ${ }^{4}$

O presente texto se insere nessa tentativa de resgatar o caráter religioso do Festival do Riso, mas sem tentar reconhecer nele elementos de um festival em particular que poderia ter-lhe servido de modelo. Pelo contrário, pretendo argumentar que o Festival do Riso é na verdade mais facilmente entendido pelo seu caráter abstrato e universal: ele seria a reunião de uma série de elementos presentes em diversas celebrações festivas religiosas, fruto da tentativa de Apuleio de criar um festival religioso que não se baseasse necessariamente num festival pré-existente, mas que possuísse características que tornassem a narrativa verossímil quando analisada por esse ponto de vista. O Festival do Riso acaba se tornando, acidentalmente, um testemunho daquilo que Apuleio entendia como um arquétipo de festival greco-romano, apresentando alguns dos elementos mais centrais e recorrentes dessas celebrações.

A noção de arquétipo de festival greco-romano que uso em minha análise se baseia na classificação feita por Jon W. Iddeng (2012) dos elementos centrais e periféricos presentes nos festivais greco-romanos. O texto de Iddeng se vale de uma abordagem politética para determinar o que é um festival greco-romano, listando uma série de características presentes nesses festivais que não são consideradas nem suficientes, nem necessárias para que um

\footnotetext{
4 "My aim in what follows is to counter the prevailing view of the Laughter Festival as a scapegoat ritual and argue instead that the narrative of Met. 3.1-12 represents a kind of integration rite enacted in the theatre. In this public space, Lucius and all other participants engage in the performance of ritual roles, the outcome of which leads not to his expulsion from the Hypatan community, but rather to a proposal for integration into it" (FRANGOULIDIS, 2002, p. 178).
} 
dado evento seja considerado um festival, mas que ainda assim são amplamente reconhecidas como características mais ou menos típicas dos festivais greco-romanos. ${ }^{5} \mathrm{~A}$ análise do episódio se pautará em determinar quais dessas características podem ser encontradas no Festival do Riso. Essa análise, aliada à noção de que o episódio é, de fato, uma ficção de Apuleio, permitirá determinar que o Festival do Riso é uma abstração que reflete os elementos típicos de um festival da Antiguidade.

\section{CONSIDERAÇÕES PRELIMINARES}

Para que nossa análise do episódio possa ser feita, é preciso, primeiramente, reforçar o caráter fictício do Festival do Riso. Dentro da narrativa, o primeiro ponto em que se pode questionar a realidade do evento é a própria divindade à qual ele é dedicado. O deus Risus não aparece como divindade em praticamente nenhum outro texto da literatura latina. Uma consulta rápida a um dicionário de latim normalmente só resultará nos sentidos mais comuns de "risus, -us" presentes na língua latina - ou seja, "riso", "piada" ou "objeto de escárnio". Alguns dicionários mencionam a personificação do Riso como divindade justamente nas Metamorfoses. Por fim, há ainda uma referência à deificação do Riso presente num epigrama fúnebre dedicado a Plauto, como nos é relatado por Aulo Gélio nas Noctes Atticae $(\mathrm{I}, 24)^{6}$. Porém, como afirma Regine

\footnotetext{
${ }^{5}$ Iddeng define a abordagem politética como "one in which a category or class is defined in terms of a broad set of criteria that are neither necessary nor sufficient, but with a certain number of defining characteristics, where none of the features has to be found in each member of the category." "(uma abordagem) na qual uma categoria ou classe é definida com um conjunto amplo de critérios que não são nem necessários nem suficientes, mas que contêm um certo número de características definidoras, nos quais nenhum dos traços precisa ser encontrado em cada um dos membros da categoria (IDDENG, 2012, p. 13).
}

6 "Postquam est mortem aptus Plautus, Comoedia luget Scaena est deserta, dein Risus, Ludus locusque Et Numeri innumeri simul omnes conlacrimarunt."

"Depois que Plauto encontrou sua morte, a Comédia chora O palco está deserto, e então o Riso, o Jogo e a Brincadeira E as Métricas inúmeras, todos, a um só tempo, choraram" (As traduções neste artigo são todas de minha autoria).
May, essa deificação do Riso, assim como a personificação dos metros plautinos no mesmo epigrama, é apenas um recurso literário utilizado para a criação de um oxímoro, no qual o próprio Riso está chorando a morte de Plauto: "Neste epigrama, o Riso não é uma deidade existente, mas uma invenção literária ad hoc não muito séria, que não deve ser encarada seriamente como um deus."

Deixando-se a esfera da religiosidade romana, encontram-se em biografias de Plutarco referências

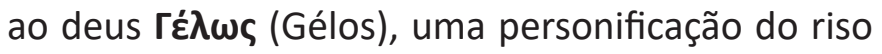
enquanto divindade, cuja estátua teria sido erguida por Licurgo, em Esparta. Outras fontes sugerem que essa divindade faria parte da comitiva de Dioniso. De qualquer forma, não se pode afirmar que tal deus seja a mesma divindade apresentada na narrativa de Apuleio.

Por fim, informações presentes no próprio texto confirmam a ideia de que o Festival do Riso não seria baseado em nenhuma outra festividade: a própria Birrena, parente de Lúcio que o convida ao festival, diz especificamente que "Amanhã haverá um Festival estabelecido desde os primeiros dias desta cidade, o qual somente nós entre os mortais dedicamos ao Riso, o mais sagrado dos deuses, com um ritual alegre e rejubilante" ${ }^{\prime \prime}$ (o grifo é meu). Assim, o próprio Apuleio já nos oferece a pista de que o Festival do Riso só acontece em Hípata. Outras comemorações de natureza semelhante ou cultos prestados a personificações do Riso em outros locais da Grécia não teriam relação com esse episódio, segundo a lógica do próprio texto.

Também é preciso determinar até que ponto Apuleio poderia ser considerado uma autoridade em termos de religião greco-romana. Além da referência mais óbvia, sua Apologia, em que o autor se defende das acusações de ter seduzido sua esposa

\footnotetext{
7 "In this epigram (...) Risus is not an existing deity, but a nonetoo serious ad hoc literary invention, not to be taken seriously as a god" (MAY, 2006).

8 "'Solemnis' inquit 'dies a primis cunalibus huius urbis conditus crastinus aduenit, quo die soli mortalium sanctissimum deum Risum hilaro atque gaudiali ritu propitiamus'"'(Met. II, 31).
} 
com artifícios mágicos - e acaba demonstrando seu conhecimento profundo sobre magia - podemos citar a passagem algo maldosa de Agostinho, que se refere a Apuleio como "sacerdote da província", dando a entender que Apuleio teria ocupado um cargo importante na hierarquia sacerdotal da África Proconsular (mas que esse teria sido seu único cargo público de importância, apesar de toda sua arte mágica) ${ }^{9}$.

Assim, é seguro afirmar que um festival religioso criado por Apuleio, mesmo sendo fictício, apresentaria características típicas daquilo que uma autoridade no assunto consideraria um festival greco-romano típico.

\section{ANÁlISE do Festival do Riso e seus ELEMENTOS RELIGIOSOS ESSENCIAIS}

Procedendo finalmente à análise, é preciso abordar o episódio do Festival do Riso buscando identificar os elementos religiosos determinados por Iddeng para a classificação de um evento como festival greco-romano arquetípico. Ao analisarmos um festival dessa maneira, é a presença de uma quantidade considerável desses elementos (chamados por Iddeng de essential features, "características essenciais") que o aproximaria de um festival greco-romano arquetípico.

\footnotetext{
9 "Apuleius enim, ut de illo potissimum loquamur, qui nobis Afris Afer est notior, non dico ad regnum, sed ne ad aliquam quidem iudiciariam rei publicae potestatem cum omnibus suis magicis artibus potuit peruenire, honesto patriae suae loco natus, et liberaliter educatus, magnaque praeditus eloquentia. An forte ista, ut philosophus, uoluntate contempsit, qui sacerdos prouinciae pro magno fuit ut munera ederet, uenatoresque uestiret, et pro statua sibi apud Oeenses locanda, ex qua ciuitate habebat uxorem, aduersus contradictionem quorundam ciuium litigaret?" Ep. CXXXVIII, 19. "Quanto a Apuleio, pois, para falarmos sobretudo dele, que sendo africano é mais conhecido a nós africanos, com todas as suas artes mágicas não pôde chegar não digo ao poder, mas nem sequer a ocupar algum cargo público judiciário, mesmo tendo nascido no berço nobre de sua pátria, tendo recebido educação liberal e sendo dotado de grande eloquência. Ou acaso dirão que desprezou essas coisas de sua própria vontade por ser filósofo aquele que, mesmo sendo sacerdote da província, tinha em grande conta fazer espetáculos, dar vestimentas a gladiadores, e que litigou com alguns cidadão de Oea, cidade da qual viera sua esposa, para que se erigisse lá uma estátua sua?"
}

O primeiro elemento apresentado por Iddeng para identificar os festivais é o seu caráter cíclico. Um festival típico, portanto, acontece com certa periodicidade, que normalmente só pode ser atestada por testemunhos literários ou por entradas em calendários religiosos. Esses períodos variam, havendo festivais que se realizavam anualmente, a cada dois anos ou a cada quatro anos. Festivais atípicos podem não ser recorrentes ou apresentarem um intervalo muito maior (como as celebrações seculares em Roma). No caso do Festival do Riso, é possível identificar sua recorrência anual por meio da fala de um dos magistrados que tenta consolar Lúcio após o julgamento. "Pois esse festival, que publicamente celebramos com solenidade a cada ano em honra do Riso, o mais grato deus, sempre floresce com uma nova invenção." 10

Festivais greco-romanos também aconteciam num local específico, contendo um ponto focal de celebração. O Festival do Riso passa facilmente pelo primeiro crivo, já que, como já foi demonstrado, a fala de Birrena deixa claro que a celebração sempre ocorria em Hípata, e em nenhum outro lugar. $\mathrm{O}$ ponto focal já exige um pouco mais de elaboração.

Em princípio, não parece haver um ponto focal claro para o Festival do Riso, devido à natureza aleatória de alguns dos acontecimentos narrados: é fácil tentar entender o teatro de Hípata como ponto focal, mas é preciso lembrar que, dentro do texto, o julgamento teria sido realizado normalmente no tribunal, não fosse pelo apelo do povo. "Com os magistrados já tendo se sentado à elevada tribuna e o pregoeiro público pedindo silêncio, de repente todos a uma só voz, por conta do grande número de pessoas, que criava o perigo de esmagamento devido à grande densidade, pediram que tão grande julgamento fosse levado ao teatro"11. Dito isso,

\footnotetext{
10 "Nam lusus iste, quem publice gratíssimo deo Risui per annua reuerticula sollemniter celebramus, semper commenti nouitate florescit" (Met III, 11).

11 "Iamque sublimo suggestu magistratibus residentibus, iam praecone publico silentium clamante, repente cuncti consona uoce flagitant, propter coetus multitudinem, quae pressurae nimia densitate periclitaretur, iudicium tantum theatro redderetur" (Met III, 2).
} 
porém, é possível supor que esse clamor popular também fosse parte da farsa do julgamento, e que o ponto focal do ritual fosse costumeiramente o teatro. Afinal, que melhor lugar para se prestar culto ao deus Riso do que o lugar onde comédias são representadas?

Um festival também precisa ser público, aberto em algum grau aos que queiram participar (embora muitos possam apresentar momentos de celebração reservados apenas aos iniciados), e está intimamente ligado ao sentimento de comunidade de uma dada população. No Festival do Riso, isso fica bastante claro, mais uma vez, com a ajuda da fala de Birrena. Afinal, um evento que só acontece em Hípata e do qual só participam os moradores da cidade (com exceção de convidados como Lúcio) certamente ajuda a reforçar os laços da comunidade.

Mais do que isso, a natureza do elemento estrangeiro desse festival (o próprio Lúcio) é relembrada ao longo da narrativa. O discurso de acusação proferido por um dos magistrados faz questão de mencionar que Lúcio é um estrangeiro. "Tendes então um réu manchado por tantos assassinatos, um réu preso em flagrante, um réu estrangeiro. Sentenciai, pois, com firmeza um estrangeiro pelo crime que vós vingaríeis severamente mesmo contra um de vossos concidadãos"12. Tais considerações reforçam o sentimento de comunidade, além de sugerir as já referidas interpretações do episódio como um rito de expiação, sendo Lúcio um bode expiatório estrangeiro, ou como um rito de iniciação à comunidade, com Lúcio recebendo honras dos cidadãos após o julgamento.

Um festival também tinha um programa ritual que deveria ser seguido por seus celebrantes. Segundo Iddeng, os elementos presentes nesse programa ritual incluiriam: os próprios celebrantes (pensando-se sobretudo nos sacerdotes e autoridades que conduzem o rito); um sacrifício; orações aos deuses; um banquete; exibição e tratamento extraordinário de objetos de culto; procissões; e atividades performáticas, como peças de teatro, jogos e competições.

Este talvez seja o elemento essencial dos festivais arquetípicos mais difícil de se encontrar no Festival do Riso. Não que a narrativa não mostre os elementos do programa ritual já listados, mas é difícil afirmar que tais acontecimentos faziam parte de um programa do Festival do Riso a ser executado em todas as celebrações. Como garantir que todo ano um estrangeiro seja levado a pensar que cometeu um triplo homicídio? Como supor que o estrangeiro em questão será escoltado até o teatro sem nenhuma tentativa de fuga? É pouco provável que todos os elementos rituais do Festival do Riso se dessem da mesma maneira o tempo todo. Mas é possível afirmar que a variação era justamente a única característica essencial para o programa ritual do Festival do Riso. Afinal, como o próprio magistrado disse a Lúcio no trecho já citado, o festival parecia "sempre florescer com uma nova invenção". É o fato de não ser sempre igual ao ano anterior que torna esse festival aprazível ao deus Riso. Nenhuma piada resiste à repetição constante.

Mesmo assim, só o que temos é o relato dessa edição do festival. E, sendo ele um evento fictício, é nessa edição que devemos nos concentrar para a análise. Assim, o sofrimento de Lúcio parece apresentar boa parte dos elementos de um programa ritual arquetípico. Os celebrantes são os próprios magistrados da cidade, que presidem ao julgamento, além de Lúcio, na qualidade de convidado especial; Lúcio também é uma vítima sacrificial, de acordo com seu próprio testemunho: " $E$ tendo enfim perambulado por todas as ruas, sou conduzido de canto em canto - à maneira daquelas procissões em que as ameaças dos maus presságios são expiadas com vítimas lustrais e sacrifícios animais levados por toda parte - e sou levado ao fórum e ao tribunal da cidade."13 - na mesma passagem já se nota como
12 "Habetis itaque reum tot caedibus impiatum, reum coram deprensum, reum peregrinum. Constanter itaque in hominem alienum ferte sententias de eo crimine quod etiam in uestrum ciuem seueriter uindicaretis" (Met III, 3).
13"Tandem pererratis plateis omnibus, et in modum eorum quibus lustralibus piamentis minas portentorum hostiis circumforaneis expiant circumductus angulatim, forum eiusque tribunal astituor" (Met III, 2) 
o ritual contou também com uma procissão; as atividades performáticas seriam, obviamente, a farsa do julgamento de Lúcio, e possivelmente a luta contra os odres de vinho. Os demais elementos listados exigem mais boa vontade do leitor: as orações aos deuses não são encontradas com tanta facilidade, a não ser que se considerem os discursos, tanto dos magistrados como de Lúcio, uma espécie de oração no sentido etimológico do termo (talvez as constantes risadas dos participantes fosse uma espécie de louvor à divindade?); também não se reconhecem objetos de culto específicos, como estátuas do deus Riso, e seria forçoso considerar os odres de vinho como referências a Dioniso - muito embora haja estátuas no teatro onde se dá o julgamento de Lúcio, e o magistrados tenham mencionado sua intenção de dedicar uma estátua ao forasteiro; não há tampouco banquetes durante a celebração, a não ser que consideremos o jantar na casa de Birrena, onde Lúcio é convidado a participar do ritual.

O último elemento essencial apresentado por Iddeng é o caráter religioso da celebração. Um festival é considerado como tal porque ocorre dentro da esfera religiosa de uma comunidade - comemorações de caráter secular, como festas de aniversário e reuniões familiares mais simples se afastam do arquétipo de festival greco-romano. Certamente, com o que foi visto até aqui, é bastante óbvia a natureza religiosa do Festival do Riso, que recebe esse nome por ser dedicado a uma divindade específica, ainda que fictícia.

\section{CONCLUSÃo}

Diante do que foi apresentado, fica claro que o Festival do Riso se encaixa perfeitamente no arquétipo de festival greco-romano delimitado por Iddeng com o auxílio da abordagem politética.

O Festival do Riso se torna também um episódio muito interessante quando colocado em contraste com outros pontos da obra, nos quais é possível reconhecer o eco de outras passagens. O já mencionado texto de Habinek aponta para a ligação existente do ponto de vista narrativo entre os três festivais representados no romance - o Festival do
Riso, o Festival de Corinto e o Festival de Ísis -, que parecem funcionar como ritos de passagem para 0 protagonista.

Há ainda diversas menções intertextuais presentes no episódio, muitas delas comparando o protagonista à figura de Sínon, um dos grandes mentirosos da literatura latina, responsável direto pela queda de Troia, segundo a Eneida de Virgílio. Os discursos de Lúcio e de Sínon, suas comparações com figuras de sacrifício e alguns traços tipicamente épicos sutilmente apresentados por Apuleio nesse episódio permitem esse interessante estudo comparativo, aprofundado por Ellen Finkelpearl no livro Metamorphosis of Language in Apuleius: A Study of Allusion in the Novel.

Essas observações são feitas no intuito de ilustrar a riqueza literária presente no Festival do Riso, que de certa forma explica o relativo silêncio dos estudiosos no que tange às suas características históricas e religiosas. Quando se aborda uma narrativa tão patentemente fictícia e fantasiosa, qualquer tentativa de encontrar dados históricos relevantes parece temerosa. Mas, embora o Festival do Riso dificilmente possa oferecer grandes contribuições quanto ao entendimento das práticas religiosas específicas da Tessália, ou da Grécia como um todo, ele abre as portas para uma observação da mentalidade religiosa. Se não há como levar ao pé da letra as descrições das etapas do Festival, certamente podemos inferir através dele aquilo que se espera de um festival. A narrativa se mostra, portanto, como a idealização de uma prática religiosa, criada pela mente de um homem capaz não só de refletir com propriedade sobre os aspectos mais elementares dessa prática, mas também de apresentá-los de maneira a fazer da narrativa um poderoso monumento literário, repleto de referência intra e extratextuais e camadas de interpretação.

À guisa de conclusão, é possível retomar o que Iddeng fala em seu texto sobre os objetivos de um festival greco-romano: um festival arquetípico fortalecia os ideais de uma comunidade; era capaz de unir seus participantes, muitas vezes através da exclusão de um elemento estrangeiro; e era, por fim, 
uma fonte de divertimento para todos os envolvidos. Tanto o Festival do Riso quanto o próprio romance de Apuleio, em suas características religiosas e literárias, cumprem esses papéis.

\section{THE FESTIVAL OF LAUGHTER IN APULEIUS' METAMORPHOSES: AN ARCHETYPE OF GRAECO-ROMAN FESTIVAL? APPLICATION OF A POLYTHETIC APPROACH}

Abstract: In this paper, we analyze the Festival of Laughter in Apuleius' Metamorphoses (II, 31 - III, 18) through the polythetic approach used by Jon W. Iddeng to define and classify graeco-roman festivals. We intend to demonstrate how Apuleius' description of a fictitious festival shows the author's own knowledge and personal experiences of what constitutes a festival, thus creating an archetype of graeco-roman festival. The Festival of Laughter presents, therefore, central features of graecoroman festivals as defined by Iddeng (2012).

Keywords: Apuleius, Metamorphoses, Festival of Laughter, graeco-roman festival
IDDENG, Jon W. What is a graeco-roman festival? A polythetic approach. In: IDDENG, Jon W. and BRANDT, J. Erasmus. Greek and Roman Festivals: Content, Meaning and Practice. Oxford: Oxford Univesity Press, 2012.

MAY, Regine. Apuleius and Drama: The Ass on Stage. Oxford: Oxford University Press, 2008.

PLUTARCH. Lives: volume 1 Theseus and Romulus, Lycurgus and Numa, Solon and Publicola. Translated by Bernadotte Perrin. Cambridge, Ma.: Harvard University Press, 1914.

ROBERTSON, Donald. S. A Greek Carnival. In: The Journal of Hellenic Studies vol. 39. 1919 (disponível em http://www.jstor.org/stable/624875)

S. AVGVSTINVS. Epistolae: Pars III Ep. CXXIV-CLXXXIV A. In: CORPVS SCRIPTORVM ECCLESIASTICORVM LATINORVM. Vindobona: Academia Litterarum Caesareae Vindobonensis, 1904.

WALSH, Patrick. G. The Roman Novel. London: Bristol Classical Press, 2006.

\section{BiBLIOGRAFIA}

APULEIUS. Metamorphoses: Books I - VI. Translated by J. Arthur Hanson. Cambridge, Ma.: Harvard University Press, 1996.

AULUS GELLIUS. Attic Nights: Books I - V. Translated by J. C. Rolfe. Cambridge, Ma.: Harvard University Press, 1927.

FINKELPEARL, Ellen D. Metamorphosis of Language in Apuleius: a study of alusion in the novel. Ann Arbor: University of Michigan Press, 1998.

FRANGOULIDIS, Stavros. The Laughter Festival as Community Integration Rite in Apuleius' Metamorphoses. In: Ancient Narrative Supplementum 1: Space in the Ancient Novel. Groningen: Barkhuis Publishing, 2002.

Witches, Isis, and Narrative: Approaches to Magic in Apuleius' Metamorphoses. Berlin: Walter de Gruyter GmbH \& Co., 2008.

HABINEK, Thomas N. Lucius' Rite of Passage. In: Materiali e discussioni per l'analisi dei testi classici no. 25, Studi sul Romanzo Antico. 1990 (disponível em http:// www.jstor.org/stable/40235966) 